\title{
Perturbation of upper gastrointestinal function by cold stress
}

\author{
D G THOMPSON, ${ }^{*}$ E RICHELSON, AND J-R MALAGELADA \\ From the Gastroenterology Unit and Departments of Pharmacology and Psychiatry, Mayo Clinic and Mayo \\ Foundation, Rochester, MN, USA
}

SUMmaRY To study the effects of stressful stimulus (cold pain) upon postprandial gastric, duodenal, and pancreatic function, nine healthy adult volunteers were intubated and then given two identical liquid meals, $(199 \mathrm{cal}(789 \mathrm{KJ}) 240 \mathrm{ml})$, each being ingested during a period of irregular fasting gastroduodenal motility. Ten minutes after each meal the subjects received, in randomised order, either a test or control stimulus. The test stimulus consisted of repeated one minute immersions of a hand into ice water, with 15 seconds recovery between immersions, for a total of 20 minutes, while for the control, water at $37^{\circ} \mathrm{C}$ was used. Serial samples of gastric and duodenal contents allowed estimation of changes in gastric emptying and acid secretion, together with pancreatic trypsin output, by a double marker perfusion technique. Measurements of blood pressure, pulse, and finger temperature acted as extra-intestinal indices of autonomic response to the stimuli. Cold pain significantly delayed gastric emptying and produced a biphasic alteration in both gastric secretion and pancreatic trypsin output, with an initial reduction during the response to the stress followed by an increase during the post-stress period. Our findings show that the normal postprandial function of the upper gut can be measurably disturbed by a stressful stimulus. The coincidence of these disturbances with other extra-intestinal autonomic changes suggests that they are a further manifestation of the somatic response to a stress.

The ability of the central nervous system to adversely affect the function of the upper gastrointestinal tract in response to diverse stressful stimuli has been appreciated for over a century, ${ }^{1}$ but knowledge of the changes which occur remains fragmentary.

Many previous studies have been anecdotal in nature and have yielded inconclusive and often contradictory results. This seems to be at least partly the result of insufficient knowledge of normal gastrointestinal physiology at the time of the performance of the studies, which prevented adequate experimental design and interpretation. In the last decade, however, a much greater understanding of normal gut function has been obtained. It is now recognised that the pattern of motor and secretory activity of the fasting upper gut in man is

\footnotetext{
* Present address: Medical Unit. The London Hospital. London E11BB. England.

Address for reprints: J-R Malagelada. Gastroenterology Unit. Mayo Clinic. Rochester. MN 55905. USA.

Received for publication 1 July 1982
}

triphasic $^{2-4}$ and, at least in the case of motility, migrates from the stomach along the small intestine. Feeding disrupts this pattern, replacing it by a more predictable pattern of activity during the time that nutrients emptied by the stomach remain in the intestine. ${ }^{5}$

With this new knowledge and with the more sensitive methods now available for measurement of gastric, duodenal, and pancreatic function, ${ }^{67}$ we decided to investigate some of the disruptive effects of the central nervous system upon the gut. The aim of the study was, therefore, to determine whether an experimentally applied stressful stimulus could significantly disturb the normal secretory and motor feeding activity of the upper gut. As a stressful stimulus, pain resulting from the immersion of a hand in cold water was chosen. This stimulus has been extensively studied in the past in the form of the cold pressor test. ${ }^{89}$ Marked alterations in sympathetic autonomic nervous activity have been shown to occur, ${ }^{10}$ but the effects of these autonomic changes upon upper gut digestive function remain unknown. 


\section{Methods}

\section{SUBJECTS}

All experimental protocols were examined and approved by the Human Studies Committee of the Mayo Clinic.

Nine healthy adult subjects (age range 20 to 62 years) gave their informed consent to participate in the study. Each subject received two identical meals per study day, with the application of a test or control stimulus after their ingestion. Three subjects repeated the study on a second day.

\section{EXPERIMENTAL PROCEDURE}

On the morning of each study day, after an overnight fast, a radiopaque multilumen polyvinylchloride tube (external diameter $6 \mathrm{~mm}$ ) was ingested, and positioned, with the aid of fluoroscopic visualisation, so that its tip lay at the duodenojejunal flexure (Fig. 1). The central tube (internal diameter $1.7 \mathrm{~mm}$ ) with multiple holes at its distal end, and an integral air vent, allowed aspiration of intestinal contents, while the other four smaller $(0.9 \mathrm{~mm}$ internal diameter) channels opening at $10 \mathrm{~cm}$ intervals from the end of the tube were used as open-tip catheters for monitoring antral and duodenal intraluminal pressure changes by the use of a standard low compliance perfusion system $^{11}$ and attached strain gauge pressure transducers (Konigsberg Instruments, model P36, Pasadena, CA). A graphic record of gastrointestinal motility at the four recording sites was then obtained by displaying the voltage output of each transducer on a paper chart recorder (MFE 1600, MFE Corp,

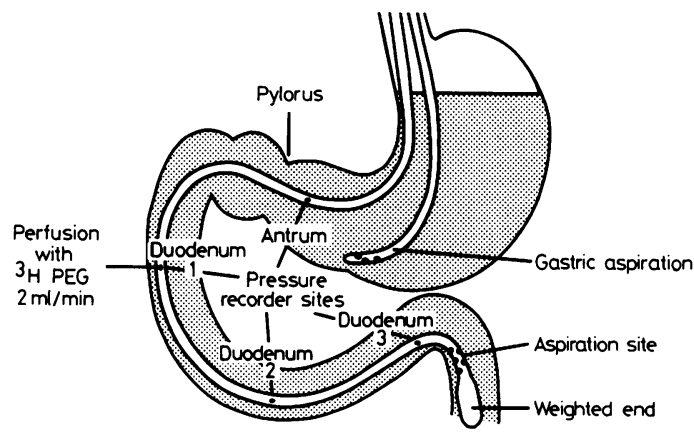

Fig. 1 Diagram of tubes used for all studies. Weighted multilumen tube, distal end at duodenojejunal flexure, allows continuous vented aspiration from its tip, monitoring of antral and duodenal motility from pressure recording sites, plus perfusion of duodenum with tritiated polyethylene glycol solution as marker of net duodenal flow. Vented gastric tube allows sampling of stomach contents.
Salem, NH). The proximal duodenal channel (duodenum 1, Fig. 1), sited approximately at the ampulla of Vater, was perfused at a rate of $2 \mathrm{ml}$ per minute with an aqueous solution of tritium-labelled polyethylene glycol $\left({ }^{3} \mathrm{H}-\mathrm{PEG}\right.$, mol wt 4000 , New England Nuclear Corp, Boston, MA) in a concentration of $20 \mu \mathrm{Ci} / \mathrm{l}$. This nonabsorbed marker allowed estimation of duodenal flow rates by dilutional methods used in our laboratory. ${ }^{6}$ The other three channels were perfused by distilled water at a rate of $0.1 \mathrm{ml} / \mathrm{min}$ to ensure their patency and to eliminate damping of pressure changes by the accumulation of gas in the tubes. The characteristics of the manometric system used in these studies have been reported. ${ }^{12}$ Response of the catheter to end occlusion was $27.5 \mathrm{~mm} \mathrm{Hg} / \mathrm{sec}^{-1}$ vs $42 \mathrm{~mm} \mathrm{Hg} / \mathrm{sec}^{-1}$, obtained by occlusion of the outflow at the level of the transducer. In vitro experiments inducing transient pressure changes at a frequency of 12 cycle/min (maximal duodenal contractile frequency) showed that the manometric system registered all waves with a mean amplitude of $96 \%$ of that recorded simultaneously with a microtip strain gauge transducer. ${ }^{12}$

After positioning of a further tube (Fig. 1) to enable sampling of stomach contents, subjects were transferred to a study area where they lay supine on a hospital bed throughout the studies, head end raised to $40^{\circ}$, to reduce the possibility of positionrelated variation in gastric emptying. ${ }^{13}$

Study commenced with a period of at least 30 minutes to allow subjects to become accustomed to the apparatus and to enable an assessment of the prevailing fasting motility pattern to be made. When irregular gastroduodenal contractions (phase II) appeared, a standard liquid meal (Table 1) was

Table 1 Constituents of test meal

\begin{tabular}{|c|c|c|c|c|}
\hline & $\begin{array}{l}\text { Total } \\
(\mathrm{g})\end{array}$ & $\begin{array}{l}\text { Carbo- } \\
\text { hydrate } \\
(\mathrm{g})\end{array}$ & $\begin{array}{l}\text { Protein } \\
(\mathrm{g})\end{array}$ & $\begin{array}{l}\text { Fat } \\
(g)\end{array}$ \\
\hline \multicolumn{5}{|l|}{$\begin{array}{l}\text { Homogenised } \\
\text { chicken soup* }\end{array}$} \\
\hline \multicolumn{5}{|l|}{ Non-fat dried } \\
\hline milk & 20 & $11 \cdot 0$ & $6 \cdot 5$ & $0 \cdot 1$ \\
\hline Whole milk & 50 & $2 \cdot 5$ & $1 \cdot 5$ & $1 \cdot 5$ \\
\hline Total & 170 & $20 \cdot 5$ & $11 \cdot 0$ & $8 \cdot 1$ \\
\hline \multicolumn{5}{|c|}{$\begin{array}{l}\text { Total energy content }=199 \mathrm{cal}(789 \mathrm{KJ}) \text {. } \\
20 \text { microcuries of }{ }^{14} \mathrm{C} \text { polyethylene glycol mol wt } 4000\left({ }^{14} \mathrm{C}-\mathrm{PEG}\right. \\
4000 \text {, New England Nuclear Corp, Boston, MA) were added to the } \\
\text { meal for the estimation of meal emptying. } \\
\text { Total volume (with added water) }=250 \mathrm{ml} \text {. } \\
\text { Volume ingested by subject }=240 \mathrm{ml}(10 \mathrm{ml} \text { taken before ingestion } \\
\text { for marker measurements). } \\
{ }^{*} \text { Canned cream of chicken soup (Campbell Soup Co, Camden, NJ } \\
08101) \text {, batch number } 03 \mathrm{EKGN} \text {. }\end{array}$} \\
\hline
\end{tabular}


ingested. Serial samples of gastric contents $(10 \mathrm{ml}$ samples) and duodenal contents (continuous measured aspirations) were then taken at 10 minute intervals for the next 90 minutes. These samples allowed estimation of gastric meal emptying, gastric secretion, gastric acid production, and pancreatic trypsin output by the double marker method, developed and validated in our laboratory ${ }^{614}$ using the ${ }^{3} \mathrm{H}-\mathrm{PEG}$ as the duodenal recovery marker and ${ }^{1+} \mathrm{C}-\mathrm{PEG}$ as the meal marker.

\section{EXPERIMENTAL DESIGN}

Ten minutes after meal ingestion, a test or a control stimulus was applied, the choice being randomly determined. The non-dominant hand of the subject was repeatedly immersed for one minute intervals into water at either $4^{\circ} \mathrm{C}$ (test) or $37^{\circ} \mathrm{C}$ (control). The hand was removed for 15 seconds between immersions, the cycles being repeated for a period of 20 minutes. With the other upper extremity, the following were determined: serial measurements of brachial blood pressure by sphygmomanometry, radial pulse rate by palpation, and digital skin temperature using a Model HT-2 skin thermometer (Autogenic Systems Inc, Berkeley, CA); these parameters acted as extra-intestinal indices of autonomic nervous system response to each stimulus. Subjective responses of the subjects were recorded on a simple questionnaire.

The completion of meal emptying was judged by a failure to aspirate further food through the gastric tube, and by the reappearance of a phase III motor pattern (migrating burst of regular contractions) which signalled a return to fasting gastrointestinal motor activity. With the reappearance of an irregular fasting contractile pattern (phase II) a second identical meal was then given, followed 10 minutes later by the other stimulus. The second study also lasted 90 minutes.

The three subjects who repeated the study on a second day received again, in random order, both a further identical test stimulus and a meal without stimulus.

\section{ANALYSIS OF PRESSURE ACTIVITY TRACINGS}

The gastroduodenal pressure activity tracings were analysed in several ways. We measured the duration of the interval between ingestion of the meal and reappearance of phase III activity (signalling return to the interdigestive motor pattern). The tracings were also examined for differences in feeding duodenal pressure activity between test and control stimuli. This was performed by determining the mean frequency and height of pressure waves in the three duodenal channels (antral phasic pressure activity being virtually absent after a liquid meal). ${ }^{3}$

STATISTICAL ANALYSIS OF DATA

The test studies were divided into a stress and a post-stress period, the stress period being determined by the duration of raised systolic blood pressure. Because the raised blood pressure is related to the perceived severity of the cold pain ${ }^{16}$ this method of division was chosen to give a more realistic index of stress response for each subject than would the use of the duration of stimulus application. The mean duration of the stress period for the group was 35 minutes, with a range of 25-45 minutes. In the comparison of test and control data for each subject, therefore, the stress period was determined and mean differences between the test and the control values were obtained for this time interval. The post-stress period comprised the remainder of the study after return of blood pressure to a steady level.

The significance of the difference between test and control during the stress period was determined by Student's paired $t$ test ${ }^{17}$ to test the hypothesis that test minus control values should not differ significantly from each other. The same approach was adopted for the post-stress period. The significance of an apparently biphasic difference between test and control values was tested by comparing the mean value of the difference for the stress period with that for the post-stress period using a paired $t$ test, the null hypothesis being that this stresspost-stress difference should not differ significantly from zero for the group.

\section{Results}

\section{QUESTIONNAIRE RESULTS}

All subjects reported that the cold water was unpleasantly painful but all were able to complete the 20 minute test period except one subject, who stopped after six minutes. No sequelae of the test were encountered and no discomfort was reported during the control stimulus.

EXTRAINTESTINAL CHANGES

Measurements of systolic and diastolic blood pressure and finger temperature altered consistently during the test stimulus compared with the control (Table 2). Pulse rate, in contrast, showed no consistent change for the group. No significant differences in any function were noted for the post-stress period (data not shown).

GASTRIC EMPTYING

Gastric emptying rates were calculated as the 
Table 2 Changes in extra-intestinal autonomic nervous system variables during the stress period

\begin{tabular}{lccc}
\hline \multicolumn{1}{c}{ Difference hetween test and control mean values } & & $\begin{array}{c}\text { Significance } \\
\text { of difference } \\
\text { (paired t test) }\end{array}$ \\
\hline$\triangle$ Mean systolic blood pressure, $\mathrm{mm} \mathrm{Hg}$ & Mean & $\pm S E M$ & $<0 \cdot(0) 1$ \\
$\triangle$ Mean diastolic blood pressure, $\mathrm{mm} \mathrm{Hg}$ & $+18 \cdot 5$ & $3 \cdot()$ & $<0 \cdot(001$ \\
$\triangle$ Mean radial pulse rate, beats per minute & $+13 \cdot 1$ & $1 \cdot 5$ & $>0 \cdot 3$ \\
$\triangle$ Mean finger temperature, degrees Celsius & $+2 \cdot 16$ & $3 \cdot 1$ & $0 \cdot(04$ \\
\hline
\end{tabular}

amount of meal (ml) emptied every 10 minutes. As shown by Figure 2, the test stimulus (cold pain) caused a striking delay in gastric emptying of the meal relative to control stimulus. The reduction in meal emptied during the stress period was $32 \pm 13 \mathrm{ml}$ (mean $\pm \mathrm{SE}$ ), which is statistically significant at the $p<0.05$ level.

\section{GASTRIC AND PANCREATIC ENZYME SECRETION}

The pattern of gastric and pancreatic enzyme secretion was altered by the test stimulus when compared with the control, with a biphasic change. Figure 3 illustrates this biphasic change by portraying mean differences $(\triangle)$ between test and control stimulus at each 10 minute interval for the duration of the study ( 90 minutes). The significance of this biphasic change in the feeding secretory response was tested by comparing the mean difference for the stress period with that for the post-stress period in each subject, using a paired $t$ test. Using this statistical approach, the biphasic change produced by cold pain upon gastric secretory volume and trypsin outputs was significant $(p=0.024$

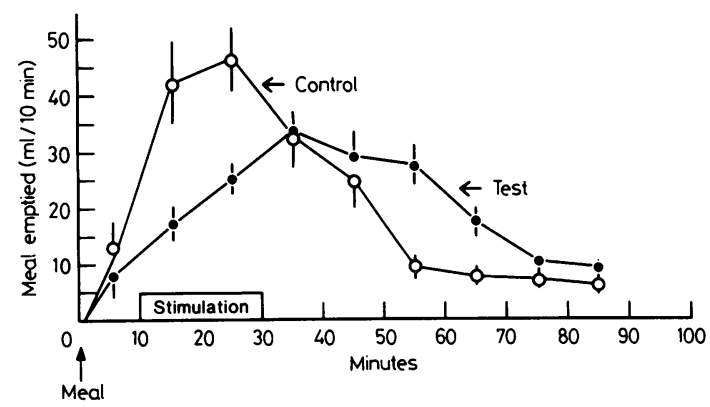

Fig. 2 Effect of cold pain on gastric emptying of meal. Rates of meal delivery into duodenum ( $\mathrm{ml} / 10 \mathrm{~min})$ during test (cold water) and control (warm water) stimuli are shown. Points represent mean $\pm S E(n=9)$ at each 10 minute sampling period. Meal was ingested at time 0. Stimulation was applied from 10 to 30 minutes postprandially. It is apparent that the test stimulus induces marked delay in rate of gastric emptying of meal relative to control stimulus. and $p=0 \cdot 016$, respectively) and borderline for acid output $(p=0.059)$. The borderline result obtained for acid output appeared to be because of an inconsistent decrease during the stress period, as the raised post-stress in acid output was highly significant $(p=0 \cdot 004)$.

\section{DUODENOGASTRIC REFLUX}

Some of the observed differences in gastric and pancreatic function could possibly have been the result of different degrees of duodenogastric reflux. This possibility was examined by comparing the quantity of duodenal marker which appeared in the gastric aspirate with both test and control studies. The test $v s$ control difference in percentage of perfused duodenal marker which refluxed into the stomach during the stress period was small (mean $1.7 \% \pm 1.2 \mathrm{SE}, \mathrm{p}=0 \cdot 20)$, however, and the differences for the total study period were similarly insignificant (mean $1 \cdot 3 \% \pm 1 \cdot 1 \mathrm{SE}, \mathrm{p}=0 \cdot 26$ ).

\section{GASTRODUODENAL MOTOR ACTIVITY}

All test and control meals induced a fed pattern recognised by a decrease in frequency of recordable antral contractions and an increase in frequency of irregular duodenal contractions. ${ }^{37}$

No appreciable differences in duodenal pressure activity during feeding were noted between test and control stimuli. Both the frequency and the height of pressure waves were similar in the stress and post-stress periods. Further, we found no consistent differences in time intervals between meal ingestion to phase III reappearance for test and control studies (mean difference: 10.1 \pm 13.9 min $( \pm S E)$, $\mathrm{p}>0 \cdot 3$ ). Thus, cold pain exerted no recognisable effect on the motility of the duodenum during feeding.

\section{REPEAT STUDIES}

In the three subjects who repeated the studies on a second day, we found no consistent differences between either the results of the two tests or those of the two controls for gastric emptying, and gastric and pancreatic enzyme secretion ( $p>0.3$ for all comparisons). 

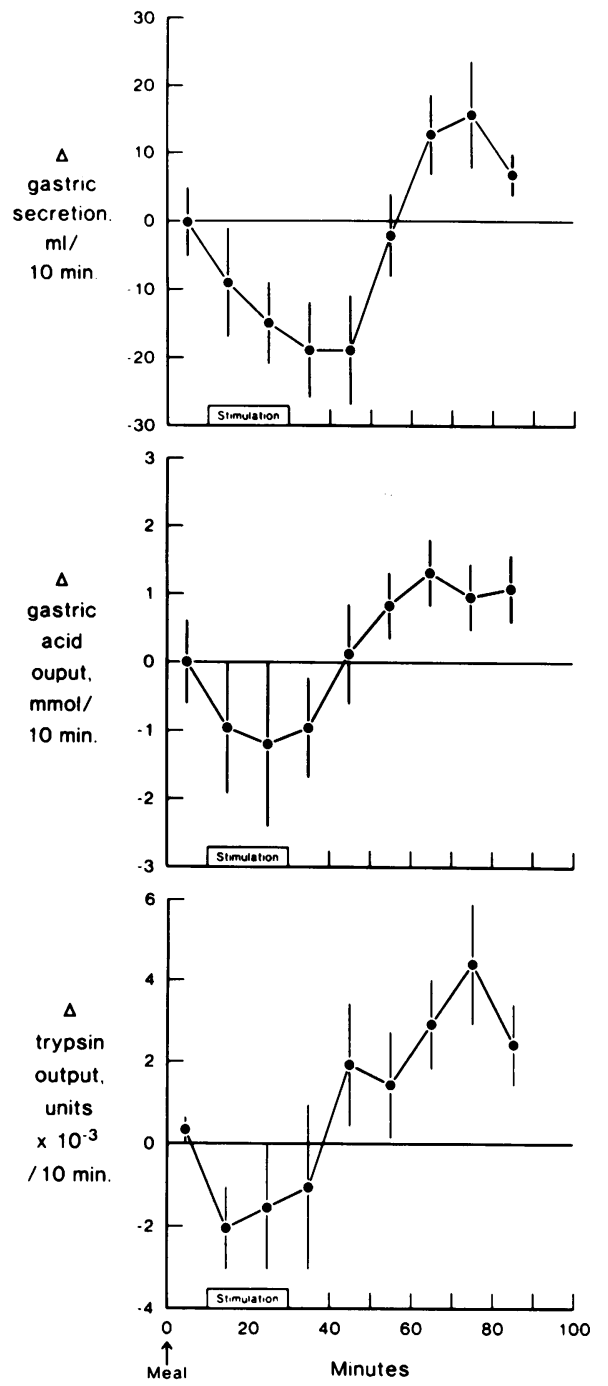

Fig. 3 Diagram of differences between gastric secretory and acid outputs and trypsin output for group (test minus control values). Points represent mean $\pm S E(n=9)$, obtained by comparing the calculated values for secretion at each 10 minute sampling period. For example, no difference between test and control stimulus would result in $\triangle$ values lining up horizontally at 0 . It is apparent that the test stimulus induced a biphasic change in all three secretory parameters, consisting of initial inhibition followed by stimulation.

\section{Discussion}

Our results show that the application of a stressful stimulus to a subject does indeed disturb the digestive function of the upper gut. Although many anecdotal and individual reports of stressful influences upon various aspects of human gut function have been reported in the literature,${ }^{1}$ the present study seems to be the first to have undertaken a systematic study of gastrointestinal responses to stress and to have been able to quantify these effects.

As an experimental stressor, cold pain has several advantages over other methods. The stimulus is simple to prepare, to standardise, and to apply, and a relatively uniform level of somatic awareness of the stimulus (pain threshold) exists throughout the general population. ${ }^{18}$ Additionally, a wealth of background information exists about its effects on the autonomic nervous system. ${ }^{819}$

The stressful effect of cold pain is recognised to depend upon the degree of individual response to the pain rather than to its perception alone,${ }^{17}$ and it thus requires the integrity of higher nervous centres. $^{819}$ The resulting changes in autonomic nervous system activity are not specific to this stimulus but are qualitatively similar to those resulting from other forms of stressful stimulation, including predominantly psychic stimuli such as mental arithmetic ${ }^{20}$ and the observation of unpleasant scenes. ${ }^{21}$ These changes thus probably represent part of the arousal phase of the general adaptive response to stressful stimuli proposed by Selye. ${ }^{22}$

The observed delay in gastric emptying appears to be an important and consistent effect of cold stress. Inhibition of gastric emptying of the meal developed during the time the stimulus was applied and only gradually returned to control levels during the succeeding hour. Gastric stasis probably results from inhibition of gastric motility, as we found no appreciable increase in duodenal motor activity, which might have suggested increased intraduodenal pressure and thus an increased resistance to gastric emptying. Inhibition of gastric motility may be because of increased sympathetic nervous activity, ${ }^{23}$ either by a direct catecholamine effect or indirectly via sympathetic stimulation of glucagon release. ${ }^{24}$ As recordable antral pressure activity is usually absent after liquid meals, ${ }^{7}$ the effect of cold stress upon gastric motility cannot be inferred from study of our antral tracings. Measurements of fundic pressure during feeding would have been of interest but they are beyond current technical capability.

The effects of cold stress on gastric secretion and acid output are intriguing in that they conform to a biphasic pattern, with an initial reduction during the stress period and a later post-stress increase. The reduction observed during the stress period is 
consistent with the findings of others using a variety of stressful stimuli including cold pain, ${ }^{25}$ mental arithmetic, ${ }^{26}$ and hypnotically induced anxiety. ${ }^{27} \mathrm{~A}$ likely explanation for this suppression is, again, increased sympathetic nervous activity ${ }^{23}$ resulting from the stress. The later increase in gastric secretion might be the result of gastric retention of the meal, a direct stimulatory effect by the stressful stimulus or a combination of both. Previous studies of fasting acid secretion under diverse stressful conditions $^{28-31}$ have also noted an apparent stimulatory effect. In one study ${ }^{30}$ stimulation of acid secretion followed an initial period of suppression, while in another ${ }^{31}$ it was inhibited by an adrenergic neuron blocking drug. Adrenaline infusion has similarly been shown to exert a delayed stimulatory effect upon acid secretion, ${ }^{32}$ as has hypoglycaemia ${ }^{32}$ a powerful stressor with marked adrenergic stimulatory effects. ${ }^{33}$

Cold pain stress also induced a biphasic change in the pancreatic enzyme response to the meal, with an initial small reduction followed by a later rise. Catecholamine-induced pancreatic inhibition is well recognised $^{3435}$ and probably explains the initial reduction. The apparent parallelism in the biphasic patterns of gastric and pancreatic secretion may reflect common mechanisms - that is, catecholamine release - mediating the secretory response of these two organs to cold pain. We did not measure catecholamine blood levels in peripheral blood in these studies but others have done so and they have shown increases in response to cold stress. ${ }^{9}$

Some of the observed stress effects could also be explained by an effect of endogenous opiates, as both beta-endorphins and enkephalins are now recognised to be released in response to experimental stress in animals. ${ }^{36} 37$ Opiates, both exogenous - for example, morphine - and endogenous, have powerful effects upon the digesting upper gut, producing a delay in gastric emptying ${ }^{38}$ a reduction of gastric acid secretion ${ }^{39}$ (and in some instances its stimulation $)^{40}$ together with an inhibition of pancreatic trypsin output. ${ }^{42}$ These possibilities need to be explored and substantiated by future studies.

While it is tempting to extrapolate our results to explain clinical gut dysfunction in terms of a response to stress, caution must prevail. The relationship between acute stress as exemplified by cold pain, and more chronic stress, is unknown and it is possible that adaptive change in responses could modify or suppress any gut disturbances. Consideration should be given, however, to the possibility that repeated periods of acute stress, perturbing normal gastrointestinal motor and secretory feeding activity, could eventually exert damaging effects upon the human upper gut.
This work was supported in part by Grant AM26428 from the National Institutes of Health. Dr Thompson's work was supported by the King Edward VII Hospital Fund for London and the Welicome Trust. Dr Malagelada is the recipient of Research Career Development Award AM-00330 from the National Institutes of Health. The authors wish to thank t... following Mayo Clinic personnel for their help in the performance of the project: A R Zinsmeister, Department of Statistics; M Wilke, Mrs J Duenes, G Thomforde, and R Tucker of the Gastroenterology Unit; and Miss B Moehnke of the Dietetic Unit. We thank Dr M Schwartz of the Department of Psychology for the loan of equipment and helpful advice on the design of the study. We also wish to thank Ms V Woyczik for typing and preparing the manuscript. Analysis of data was performed using the Clinfo (TM) data analysis system.

A preliminary report of part of this work was presented at the Plenary Session of the Meeting of the British Society of Gastroenterology in September 1981. Gut 1981; 22: A874.

\section{References}

1 Wolf S. The psyche and the stomach. Gastroenterology 1981; 80: 605-14.

2 Stanciu C, Bennett JR. The general pattern of gastroduodenal motility: 24 hour recordings in normal subjects. Rev Med Chir Soc Med Nat Iasi 1975; 79: 31-6.

3 Vantrappen G, Janssens J, Hellemans J, Ghoos Y. The interdigestive motor complex of normal subjects and patients with bacterial overgrowth of the small intestine. J Clin Invest 1977; 59: 1158-66.

4 Vantrappen G, Peeters TL, Janssens J. The secretory component of the interdigestive migrating motor complex in man. Scand J Gastroenterol 1979; 14: 663-7.

5 De Wever I, Eeckhout C, Vantrappen G, Hellemans J. How does oil disrupt the interdigestive myoelectric complex? In: Christensen J, ed. Gastrointestinal motility. New York: Raven Press, 1980: 295-7.

6 Malagelada J-R, Longstreth GF, Summerskill WHJ, Go VLW. Measurement of gastric functions during digestion of ordinary solid meals in man. Gastroenterology 1976; 70: 203-10.

7 Rees WDW, Go VLW, Malagelada J-R. Antroduodenal motor responses to solid-liquid and homogenized meal. Gastroenterology 1979; 76: 1438-42.

8 Hines E-A, Brown GE. A standard stimulus for measuring vasomotor reactions: its application in the study of hypertension. Mayo Clinic Proc 1932; 7: 332-5.

9 Lovallo W. The cold pressor test and autonomic 
function: a review and integration. Psychophysiology 1975; 12: 268-82.

10 Reiser MF, Ferris EB. The nature of the cold pressor test and its significance in relation to neurogenic and humoral mechanisms in hypertension. $J$ Clin Invest 1948; 27: 156-63.

11 Arndorfer RC, Stef JJ, Dodds WJ, Linehan JH, Hogan WJ. Improved infusion system for intraluminal esophageal manometry. Gastroenterology 1977; 73: 23-7.

12 Kerlin P. Phillips SF. Variability of motility of the ileum and jejunum in healthy humans. Gastroenterology 1982; 82: 694-700.

13 Burn-Murdoch R, Fisher M, Hunt JN. Does lying on the right side increase the rate of gastric emptying? $J$ Physiol 1980; 302: 395-8.

14 Malagelada J-R, Go VLW, Summerskill WHJ. Different gastric, pancreatic and biliary responses to solidliquid or homogenized meals. Dig Dis Sci 1979; 24: 101-10.

15 Rees WDW, Malagelada J-R, Miller LJ, Go VLW. Human interdigestive and postprandial gastrointestinal motor and gastrointestinal hormone patterns. Dig Dis Sci 1982; 27: 321-9.

16 Hardy JD, Wolff HG, Goodell H. The pain threshold in man. Am J Psychiatry 1943; 99: 744-51.

17 Snedecor GW, Cochran WG. Statistical methods. Iowa: The Iowa State University Press, 1967.

18 Schumacher GA, Goodell H, Hardy JD, Wolff HG. Uniformity of the pain threshold in man. Science 1940; 92: $110-2$

19 Wolff $\mathrm{HH}$. The mechanism and significance of the cold pressor response. $Q J$ Med 1951; 20: 261-73.

20 Ulrych $M$. Changes of general haemodynamics during stressful mental arithmetic and non-stressing quiet conversation and modification of the latter by betaadrenergic blockade. Clin Sci 1969; 36: 453-61.

21 Obrist PA, Gaebelein CJ, Zeller ES et al. The relationship among heart rate, carotid $\mathrm{dP} / \mathrm{dt}$ and blood pressure in humans as a function of the type of stress. Psychophysiology 1978; 15: 102-15.

22 Selye H. Stress in health and disease. Boston: Butterworths, 1976.

23 Furness JB, Costa M. The adrenergic innervation of the gastrointestinal tract. Ergeb Physiolog 1974; 69: $1-51$.

24 Bloom SR, Edwards AV, Vaughn NJA. The role of the sympathetic innervation in the control of plasma glucagon concentrations in the calf. J Physiol 1973; 233: 457-66.

25 Lass N, Doron O, Gilat T. Gastric acid secretion in cold urticaria. Dig Dis Sci 1980; 25: 526-8.

26 Badley LE, Spiro HM, Senay EC. Effect of mental arithmetic on gastric secretion. Psychophysiology 1969 5: 633-7.

27 Eichorn R, Tracktir J. The effect of hypnotically induced emotions upon gastric secretion. Gastroenterology 1955; 29: 432-8.

28 Goldman MC. Gastric secretion during a medical interview. Psychosom Med 1963; 25: 351-6.

29 Miller RJ. Gastric response to foods. The influence of worry on gastric digestion. Science 1920; 52: 253-4.

30 Stacher G, Berner P, Naske R, Schuster P. Starker H Schulze D. Effect of bromazepam on gastric acid secretion related to hypnotically induced anxiety. Int $J$ Clin Pharmacol 1976; 14: 126-31.

31 Shay H. Emotional stress and parietal cell mass. Am J Dig Dis 1959; 4: 846-70.

32 French JD, Longmire R, Porter R, Movius H. Extravagal influences on gastric hydrochloric acid secretion induced by stress stimuli. Surgery 1953; 34: 621-32.

33 Vendsalu A. Studies on adrenaline and noradrenaline in human plasma. Acta Physiol Scand 1960; 49: suppl 173.

34 Mann FC, McLachlin LC. The action of adrenaline in inhibiting the flow of pancreatic secretion.J Pharmacol Exp Ther 1917; 10: 251-9.

35 Harper A, Vass C. The control of the external secretion of the pancreas in cats. J Physiol 1941; 99: 415-35.

36 Gullemin R, Vargo T, Rossier J et al. Beta endorphin and adrenocorticotrophin are secreted concomitantly by the pituitary gland. Science 1977; 197: 1367-9.

37 Viveros $\mathrm{OH}$, Diliberto EJ, Hazum E, Chang K Enkephalins as possible adrenomedullary hormones: storage, secretion and regulation of synthesis. In: Costa $\mathrm{E}$, Trabucchi $\mathrm{M}$, eds. Neural peptides and neuronal communication. New York: Raven Press, 1980.

38 Kreuger $\mathrm{H}$. The action of morphine on the digestive tract. Physiol Rev 1937; 17: 619-45.

39 Feldman M, Walsh JH, Taylor IL. Effect of naloxone and morphine on gastric acid secretion and on serum gastrin and pancreatic polypeptide concentrations in humans. Gastroenterology 1980; 79: 294-8.

40 Yamaguchi I. A comparative study on the mechanism of action of morphine on gastric acid secretion in dogs. Jpn J Pharmacol 1974; 24: 779-86.

41 Konturek SJ, Tasler J, Cieszkowski M, Mikos E, Coy DH, Schally AV. Comparison of methionineenkephalin and morphine in the stimulation of gastric acid secretion in the dog. Gastroenterology 1980; 78: 294-300.

42 Konturek SJ, Tasler J, Cieszkowski M, Mikos E, Coy DH, Schally AV. Inhibition of pancreatic secretion by enkephalin and morphine in dogs. Gastroenterology 1978; 74: 851-5. 